\title{
Anomalous litters in hybrid mice and the retention of spermatozoa in the female tract
}

\author{
Suzanne L. Ullmann \\ Department of Zoology, University of Glasgow, Glasgow G12 8QQ, U.K.
}

\begin{abstract}
Summary. Suspected superfetation was investigated in a Glasgow hybrid stock of mice. The male was removed either (i) a few days before parturition, or (ii) immediately after mating and on 23 and 25 occasions, respectively, a second litter was born. Members of the anomalous litters were inbred for 10 generations, but the incidence of supernumerary litters did not increase beyond $2.5 \%$.

The anterior part of over 500 reproductive tracts, at various stages of pregnancy and after parturition, were serially sectioned but a second set of embryos was not found. The second gestation was of normal length and superfetation was not therefore considered to be the cause of the anomalous litters. In two females, one non-pregnant and one pregnant, spermatozoa were found in the uterus and oviducts 8 days after mating and in distended uterine glands 15 days after mating respectively.

It is concluded that the anomalous litters were derived from the fertilization of eggs ovulated at the post-partum oestrus by spermatozoa which had been retained in the female tract for at least 23 days.
\end{abstract}

\section{Introduction}

Superfetation is a rare event in mammals and is distinguishable from that of "parallel embryonic development" in which differences in embryonic stages are due to variations in the time of implantation among the same set of ova (Weichert, 1942). Rollhauser (1949) states that "superfetation should be defined as ovulation, fertilization, and implantation of a second set of eggs during pregnancy". This definition, however, has not always been adhered to in discussions of the subject (Deanesly, 1966; Leonard \& Linden, 1972). Apparent spontaneous superfetation has been reported in a number of species (Radash, 1921; Studdiford, 1936; Deanesly, 1966; Leakey, 1969; Martinet, Legouis \& Moret, 1970), including man (Murless \& McLaughlin, 1937; Scrimgeour \& Baker, 1974) and mouse (Sumner, 1916; Crew \& Mirskaia, 1930; Littleford \& Gysin, 1944; Rollhauser, 1949; Bloch, 1952; Barnett \& Munro, 1970; Leonard \& Linden, 1972).

The present investigation was undertaken (i) to examine in detail the stock of mice claimed by Barnett \& Munro (1970) to produce supernumerary litters; and (ii) to elucidate the mechanisms which allowed females to produce a second (anomalous) litter after a normal parturition, in the absence of post-partum mating.

\section{Materials and Methods}

\section{Husbandry}

The mice were of a mixed stock obtained by crossing four inbred strains, A2G/Tb, A/Tb, C57BL/ Tb and GFF (Barnett \& Little, 1968; Barnett \& Munro, 1970), and are referred to as the "Glasgow hybrids'. The reproductive performance of over 500 mice was examined during the period 1970-1974.

The females were kept in separate cages into which the male was introduced for mating. Males were removed a few days before parturition (i.e. the procedure of Barnett \& Munro, 1970), or as soon as a vaginal plug was detected, and after parturition the female was left alone for a further 24 
days. If she showed no signs of pregnancy, she was again mated and the procedure repeated. Cages were checked daily for vaginal plugs and litters. Records were kept of all matings and births and litters produced by each female were numbered consecutively. First litters were always weaned in order to maintain the stock. Second litters were killed at birth to avoid the delay of implantation caused by lactation of the third litter. The second litter was only retained if the first did not survive or contained mice of only one sex. The mice were weaned at 3 weeks of age and outbred at 5 weeks. Anomalous litters were inbred (brother-sister mated) for 10 generations but were otherwise treated as were the outbred colony. The animals were maintained at $21^{\circ} \mathrm{C}$ in a $12 \mathrm{hr}$ light :12 hr dark lighting regimen. Compound diet pellets (Diet 41: Dixon \& Sons, Ware, Herts; or Breeding Diet: Oxoid Ltd, London) and water were provided in excess.

\section{Histology}

Female mice were killed at 7-15 months of age, at various stages of the reproductive cycle. The animals were killed with chloroform and the reproductive tract was removed and fixed in aqueous Bouin's solution. The uterus was sectioned some distance below the utero-tubal junction and, like the ovaries and oviducts, was embedded in $52^{\circ} \mathrm{C}$ paraffin wax, serially sectioned at $10 \mu \mathrm{m}$ and stained with Mayer's acid haemalum and alcoholic eosin. In addition, several complete tracts were serially sectioned. Some of the sections were stained in Martius-scarlet-blue (Lendrum, Frazer, Slidders \& Henderson, 1962) to show up the connective tissue.

\section{Results}

\section{Anomalous litters}

Incidence. As shown in Table 1, 22/304 litters ( $7 \%$ ) produced by the outbred mice and 30/1149 litters $(2.5 \%)$ produced by the inbred mice were anomalous. Some of this discrepancy was probably due to temporary problems with the diet which was apparent for the inbred mice but not the outbred colony which had ceased to produce any anomalous litters by this time (generations 55-60). Most females produced only one anomalous litter, but two such litters were produced by two outbred and one inbred female. Two outbred and two inbred females contained supernumerary fetuses when killed. The anomalous litters occurred at any time: outbred mice, 5 litters at the 2 nd pregnancy, 9 at the $3 \mathrm{rd}, 4$ at the $4 \mathrm{th}, 1$ at the 5th and 3 at the $6 \mathrm{th}$; inbred mice, 8 at the $2 \mathrm{nd}, 8$ at the $3 \mathrm{rd}, 7$ at the 4 th, 3 at the 5 th, 3 at the 6 th and 1 at the 7 th pregnancy.

Table 1. The number of anomalous litters in 12 generations (no data for 51 st generation) of outbred and 10 generations of inbred Glasgow hybrid mice

\begin{tabular}{lrrrrrrrrrrrr}
\hline Outbred & & & & & & & & & & & 56 & 59 \\
Generation & 48 & 49 & 50 & 52 & 53 & 54 & 55 & 56 & 57 & 58 & 59 \\
Number of females & 20 & 22 & 20 & 20 & 20 & 30 & 30 & 30 & 30 & 30 & 50 & 20 \\
Anomalous litters & $4^{*}$ & 4 & $4 \dagger$ & 3 & 2 & 5 & 0 & 0 & 0 & 0 & 0 & 0
\end{tabular}

\begin{tabular}{lrrrrrrrrrr}
\hline Inbred & 1 & 2 & 3 & 4 & 5 & 6 & 7 & 8 & 9 & 10 \\
Generation & 26 & 43 & 35 & 42 & 32 & 46 & 53 & 31 & 63 & 57 \\
Number of females & $8 \ddagger$ & 4 & 1 & 1 & 1 & 2 & 4 & 2 & 4 & 3 \\
Anomalous litters & 8 & &
\end{tabular}

* Produced by 2 females which each had 2 anomalous litters.

$\dagger$ Produced by 3 females; two of the litters were found in utero.

$\ddagger$ Produced by 6 females; one litter found in utero.

Gestation length. The duration of gestation was measured from the time the vaginal plug was detected (Day 1) for normal litters; and from the day after parturition (Day 1) for the anomalous 
litters. The range for normal litters was 15-26 days (mean 21.5 days) and for the anomalous litters 16-34 days (mean 23 days).

Litter size. The numbers of young in the normal and anomalous litters were analysed and those in the latter were significantly greater than those in the former (Table 2).

Table 2. The litter sizes of normal litters born to outbred and inbred mice and of their anomalous litters

\begin{tabular}{|c|c|c|c|c|c|c|c|c|c|c|c|c|c|c|c|c|c|}
\hline & \multicolumn{16}{|c|}{ Litter size } & \multirow[b]{2}{*}{ Mean \pm S.E.M. } \\
\hline & 1 & 2 & 3 & 4 & 5 & 6 & 7 & 8 & 9 & 10 & 11 & 12 & 13 & 14 & 15 & 16 & \\
\hline Normal outbred & 1 & 3 & 5 & 6 & 6 & 7 & 5 & 4 & 5 & 5 & 4 & 3 & 6 & 3 & 1 & 1) & \\
\hline Normal inbred & 1 & 4 & 7 & 7 & 10 & 13 & 10 & 16 & 9 & 10 & 6 & 1 & 1 & 1 & 0 & $0\}$ & $7 \cdot 1 \pm 0 \cdot 24^{*}$ \\
\hline $\begin{array}{l}\text { Anomalous (inbred } \\
\text { and outbred) }\end{array}$ & 0 & 0 & 3 & 3 & 5 & 5 & 2 & 1 & 7 & 7 & 7 & 4 & 3 & 1 & 1 & 0 & $8.7 \pm 0.43^{*}$ \\
\hline
\end{tabular}

* $t=3.29, \quad$ d.f $=206, \quad P<0.001$.

Body weight. There was no difference in the mean body weights of young from normal and anomalous litters at birth $(1 \cdot 5(\mathrm{~N}=53)$ and $1 \cdot 5(\mathrm{~N}=44) \mathrm{g})$ and at weaning $(9 \cdot 4(\mathrm{~N}=23)$ and $9 \cdot 5$ $(\mathrm{N}=41) \mathrm{g})$.

Sex ratio. There were 118 males and 115 females born in 33 anomalous litters.

\section{Histology}

Ovarian. There was a high incidence of polyovular follicles in the Glasgow hybrid mice. At least one polyovular follicle was found in $37 \%$ of the outbred and $27 \%$ of the inbred mice at autopsy. No correlation was found between the occurrence of polyovular follicles and anomalous litters. There was no evidence of ovulation occurring during pregnancy.

Oviducal. The oviducts of over 200 females isolated immediately after mating were examined in serial sections between Days 10 and 15 of pregnancy. No free blastocysts equivalent to those found during lactational delay of implantation were found.

Uterine. In some $(1.3 \%)$ of the uteri examined, the uterine glands were greatly distended (up to $1 \mathrm{~mm}$ in diameter), the vesicles bulging into the uterine lumen and thus partly occluding it ( $\mathrm{Pl} .1$, Fig. 3). The vesicles were usually empty but some contained a coagulum after fixation and staining. In other vesicles large accumulations of rounded cells, occasionally bi- or trinucleate, were seen. A systematic search for the presence of spermatozoa was undertaken in serial sections of the oviducts and utero-tubal junction and the upper part of the uterus of females killed at various times after mating (3-25 days). Over 500 specimens were thus surveyed, and in two spermatozoa in substantial numbers were found. The male had been removed 8 days before autopsy of one female which was not pregnant although a vaginal plug had been found. The uteri were distended with seminal fluid in which spermatozoa were dispersed or clustered (PI. 1, Figs 1, 2 and 4). Spermatozoa were also located in folds of the utero-tubal junction which was patent and in the oviduct adjacent to the junction. The spermatozoa in the oviducal lumen were associated with large cells containing spherical nuclei, probably desquamated from the lining epithelium, but no spermatozoa were found in the more anterior parts of the oviduct. There were no spermatozoa in the small, coiled uterine glands of this animal, but in the other there were many glandular spermatozoa, especially in the distended vesicles. This female was 15 days pregnant and the male had been removed immediately the vaginal plug was detected. Many of the spermatozoa were clustered together and heads and tails were often detached. In neither specimen were leucocytes evident in the regions storing spermatozoa.

One inbred female, which had had one litter, was killed at $10 \frac{1}{2}$ months of age. Eleven swellings were present in the uterus, 3 on one side and 8 on the other. The second swelling from the oviducal end in the horn with 8 swellings was larger than the others and contained 3 embryos. All 13 embryos were aged about 7 days and corresponded to $6 \mathrm{CL}$ on one side and 13 on the other. 


\section{Discussion}

The Glasgow hybrid mice manifest a number of structural and functional peculiarities but, at least as far as the 10th generation, no deleterious effects of inbreeding have been detected. About $30 \%$ of the inbred mice possess polyovular follicles, but this characteristic does not appear to be related to the ability to produce anomalous litters. It is difficult to understand why no anomalous litters were produced by any of the outbred mice for 6 generations. The discrepancy between the incidence of anomalous litters in the outbred mice $(7 \%$ ) and inbred mice $(2.5 \%)$ is also puzzling, but may be due to a dilution effect. The occurrence of anomalous litters could be due to (1) ovulation and fertilization from insemination during pregnancy; (2) the delay of implantation of some of the embryos produced at the original mating; or (3) the retention, in the tract of the female, of spermatozoa which fertilize eggs released at the normal post-partum oestrus.

The first explanation cannot be valid for the Glasgow hybrid mice since (i) no evidence of ovulation during pregnancy was found, and (ii) over half the anomalous litters (25) were born after removal of the male from the cage of the female as soon as a vaginal plug was found. These experiments indicate that only one copulation is necessary for the genesis of both litters.

The differential implantation of blastocysts (Explanation 2) has been assumed most frequently to be the cause of superfetation (Barnett \& Munro, 1970; Leonard \& Linden, 1972; Scrimgeour \& Baker, 1974). This does not appear to be true for the Glasgow mice because no embryos of different ages were found. Moreover, if the anomalous litters were due to embryo storage, it would be necessary to postulate either a smaller litter at each parturition because only the normal number of eggs were ovulated, or the ovulation of twice the normal number of eggs. Leonard \& Linden (1972) stated that "the litter size of both pregnancies together approaches that normally found in a single pregnancy" in the CBA mice which they claimed were experiencing superfetation. However, Leonard \& Linden (1972) had only four specimens and the present results and those of Barnett \& Munro (1970: Table 2) show that the anomalous litters are in fact larger than the normal litters.

The retention of spermatozoa in the female reproductive tract (Explanation 3) is not unknown (Howarth, 1974). The experiments of Wislocki \& Snyder (1931) on induced superfetation in the rabbit by superovulation and artificial insemination demonstrated that spermatozoa can reach a "second set of ova without having been deleteriously affected by either blastocysts or the changes in the mucosal lining of the uterus and tubes following the initial mating". The classic example is found in temperate-zone bats which may store spermatozoa during hibernation. Racey (1973) has shown that spermatozoa of the pipistrelle bat may still be viable and fertile after $6 \frac{1}{2}$ months. Human spermatozoa are claimed to exist for 4 weeks (Radash, 1921 : p. 340). Doak, Hall \& Dale (1967) have demonstrated motile spermatozoa in the uterine lumen of the bitch as late as 11 days after copulation; clusters of spermatozoa were observed mostly in the uterine glands, with just a few in the oviducts and ovarian bursa. Martinet \& Raynaud (1973) have reported the storage of spermatozoa in the uterine glands of the captive European hare, and offer this as an explanation of the high incidence (60\%) of superfetation observed in these animals. It is, however, difficult to see the advantage of such a mechanism to the hare, since ovulation only occurs in response to copulation.

The retention of spermatozoa in the uterus and the fertilization of eggs ovulated at a normal oestrus could explain the anomalous litters in the Glasgow hybrid mice. When calculated from the preceding parturition the gestation lengths of most of the anomalous litters fell within the normal

\section{EXPLANATION OF PLATE 1}

Fig. 1. Section through the oviduct of a mouse 8 days after finding a vaginal plug and removal of the male, showing spermatozoa in the lumen and in the folds of the lining epithelium.

Fig. 2. Uterus of the same animal as in Fig. 1 showing distension with seminal fluid in which spermatozoa are clumped and dispersed.

Fig. 3. A tangential section of the uterus of a pregnant mouse killed 15 days after finding a vaginal plug showing the vesiculate uterine glands.

Fig. 4. Higher power of the uterus in Fig. 3, showing spermatozoa in the lumen of a distended gland. 
PLATE 1
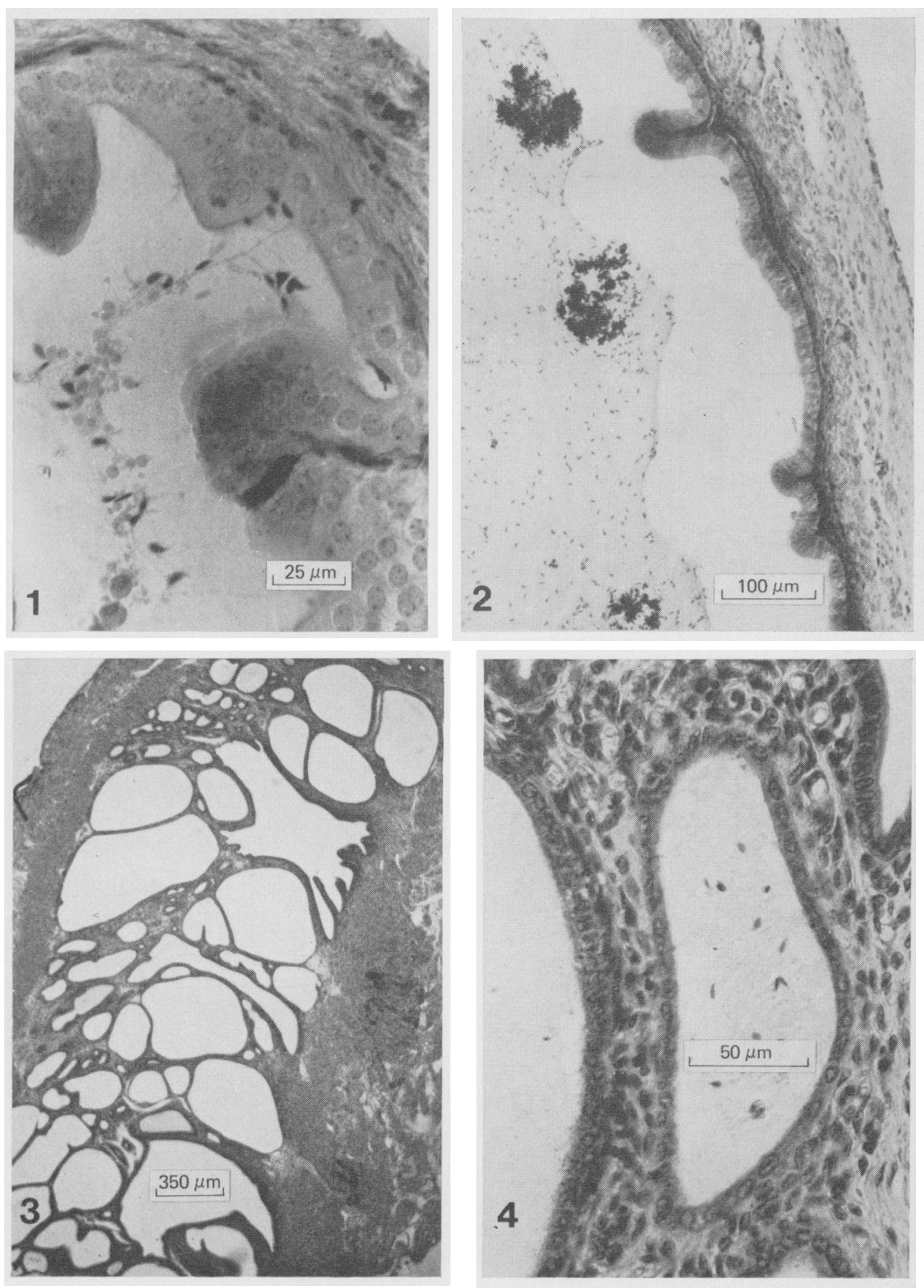
range. The interval between the two parturitions in individual females, however, was sometimes far longer (28, 32, 33 and 34 days). This was probably due to the usual lactational delay of implantation when the previous litter was being suckled, or to failure of ovulation at the post-partum oestrus and ovulation and conception at a subsequent oestrus. Such a mechanism (sperm retention coupled with delayed ovulation) could explain the lengthy gestations of 27 and 35 days following normal mating found by Leonard \& Linden (1972) and was predicted on theoretical grounds by Sumner (1916). This conclusion does not, however, exclude the possibility of true superfetation occurring in some mice. Such an interpretation is indeed the only one possible to account for the very short gestation of 13 days recorded by Sumner (1916) for Peromyscus, the two instances noted by Littleford \& Gysin (1944) and the single instance directly observed by Rollhauser (1949).

The production of "fatherless" litters (Barnett \& Munro, 1970) by means of retention of spermatozoa in the female reproductive tract is supported by the above evidence. The finding of spermatozoa in the uterus in two mice indicates that this is possible, but the discrepancy between the numbers of females in which spermatozoa were found $(0.4 \%)$ and those producing anomalous litters $(3.5 \%)$ is larger than expected. Direct evidence for the prolonged viability of stored uterine spermatozoa in this stock of mice awaits demonstration. This could be achieved by the moist impression and flushing techniques, which were found by Doak, Hall \& Dale (1967) to be preferable to sections for detecting spermatozoa in the uterus, or the insemination of virgin mice, or in vitro fertilization of eggs by stored spermatozoa.

The mechanism which allows survival of spermatozoa within the mouse uterus is, at present, completely unknown. Possibilities include (a) a failure of phagocytosis by leucocytes which normally dispose of uterine spermatozoa within $24 \mathrm{hr}$ of insemination (Austin, 1957; Reid, 1965a, b); (b) the presence of nutrients not normally available to the spermatozoa; (c) delayed capacitation of spermatozoa. The absence or scarcity of leucocytes from sites storing spermatozoa (see p. 16) has been reported for the domestic hen (Lake, 1967) and for bats (Racey, 1975). The association of desquamated epithelial cells and stored spermatozoa (see p. 15) has been described in the spermatheca of a newt (Dent, 1970), and may have a nutritive function. Reid (1965a) has suggested that only capacitated spermatozoa are phagocytosed. Recent experiments with hamster gametes indicate that capacitation occurs in the Fallopian tubes rather than in the uterus, and that the active component resides exclusively in the cumulus oophorus (Gwatkin, Anderson \& Hutchison, 1972; Gwatkin \& Andersen, 1973). In the mouse too the cumulus has been implicated in capacitation (Gwatkin, Anderson \& Williams, 1974) and the utero-tubal junction is said to close shortly after mating (Zamboni, 1972). If the normal site of capacitation is the oviduct, spermatozoa of the Glasgow hybrid mice may sometimes become trapped in the uterus with the closure of the utero-tubal junction, thus failing to become capacitated and consequently phagocytosed. If they subsequently avoid being expelled from the uterus in the normal way-perhaps because they are lodged within uterine crypts or vesicles-they would be available for fertilizing eggs ovulated at the next oestrus. Although the uterine spermatozoa in the non-pregnant mouse in this study seemed quite normal at the light microscope level, many of the spermatozoa, in the pregnant animal appeared to have detached tails. Such defects, however, need prevent neither sperm transport into the oviduct, nor fertilization. It has recently been demonstrated that "motility is not an essential prerequisite for cell passage from the uterus into the oviduct" (Zamboni, 1972), and that apparently defeetive spermatozoa can ascend to the ampulla and participate in fertilization (Smith, Oura \& Zamboni, 1970). There is nothing inherently improbable in the prolonged viability of mouse spermatozoa and the postulated genesis of the anomalous litters. Only further research, however, can elucidate the validity of these hypotheses.

I express my sincere gratitude to Professor S. A. Barnett for the gift of his colony of hybrid mice, for suggesting the problem and for his continued interest in the course of this work; Professor D. R. Newth for his encouragement, and critical reading of the manuscript; Mrs M. Mason, for histological assistance; Mr P. Rickus, for help with the photography; and Mrs A. O'Rourke for tending the mouse colony. This work was supported by M.R.C. grant No. G972/826/B. 


\section{References}

Austin, C.R. (1957) Fate of spermatozoa in the uterus of mouse and rat. J. Endocr. 14, 335-342.

Barnett, S.A. \& LitTle, M.J. (1968) Conception and parturition of mice at two temperatures. $J$. Reprod. Fert. 15, 195-304.

BARNetT, S.A. \& MUNRo, K.M.H. (1970) Superfoetation of mice. Nature, Lond. 227, 1343-1344.

BLOCH, S. (1952) Untersuchungen über Superfetation an der Maus. Schweiz. med. Wschr. 82, 632-637.

Crew, F.A.E. \& Mirskaia, L. (1930) Mating during pregnancy in the mouse. Nature, Lond. 125, 564.

DEANESLY, R. (1966) The endocrinology of pregnancy and foetal life. In Marshall's Physiology of Reproduction, 3rd edn, Vol. 3, pp. 891-1063. Ed. A.S. Parkes. Longmans Green, London.

DENT, J. (1970) The ultrastructure of the spermatheca in the red spotted newt. J. Morph. 132, 397-427.

Doak, R.L., Hal., A. \& Dale, H.E. (1967) Longevity of spermatozoa in the reproductive tract of the bitch. J. Reprod. Fert. 13, 51-58.

GWATKin, R.B.L. \& ANDERSEN, O.P. (1973) Effect of glycosidase inhibitors on the capacitation of hamster spermatozoa by cumulus in vitro. J. Reprod. Fers. 35, $565-567$.

Gwatkin, R.B.L., Andersen, O.F. \& Hutchison, C.F. (1972) Capacitation of hamster spermatozoa in vitro: the role of cumulus components. J. Reprod. Fert. 30, 389-394.

Gwatkin, R.B.L., Andersen, O.F. \& Williams, D.T. (1974) Capacitation of mouse spermatozoa in vitro: involvement of epididymal secretions and cumulus oophorus. J. Reprod. Fert. 41, 253-256.

HowARTH, B., JR (1974) Sperm storage: as a function of the female reproductive tract. In The Oviduct and its Functions, pp. 237-270. Eds A. D. Johnson \& C. W. Foley. Academic Press, New York.

LAKE, P.E. (1967) The maintenance of spermatozoa in the oviduct of the domestic fowl. In Reproduction in the Female Mammal, pp. 254-266. Eds G. E. Lamming \& E. C. Amoroso. Butterworth, London.

LEAKEY, L.S. (1969) Presumed superfoetation in an Erythrocebus patas monkey. Nature, Lond. 223, 754.

Lendrum, A.C., Fraser, D.S., Slidders, W. \& HenDERSON, R. (1962) Studies on the character and staining of fibrin. J. clin. Path. 15, 401-413.

LeONARD, A. \& Linden, G. (1972) Superfoetation in CBA mice. Experientia 28, 159.
LitTLFFoRd, R.A. \& GYSIN, H.M. (1944) Observations on superfetation in mice. Anat. Rec. 89, 507-513.

Martinet, L. \& Raynaud, F. (1973) Survie prolonguée des spermatozoides de la hase: explication de la superfoetation. Colloques de l'Institut National de la Santé et de la Recherche Médicale 26, 295-307.

Martinet, L., Legouis, J.J. \& Moret, B. (1970) Quelques observations sur la reproduction du Lièvre européen (Lepus europaeus) en captivité. Annls Biol. anim. Biochim. Biophys. 10, 195-202.

Murless, B.C. \& Mclaughlin, F.L. (1937) Does superfoetation occur? Report of a possible case. Br.med.J.i, 1309-1311.

RACEY, P.A. (1973) The viability of spermatozoa after prolonged storage by male and female bats. Period. biol. 75, 201-205.

RACEY, P.A. (1975) The prolonged survival of spermatozoa in bats. Biol. J. Linn. Soc. 7, 385-416.

RADASH, H.E. (1921) Superfoetation or superfecundation? Surgery, Gynec. Obstet. 32, 339-352.

REID, B.L. (1965a) Fate of uterine spermatozoa in the mouse post-coitum. Aust.J. Zool. 13, 189-199.

ReID, B.L. (1965b) Fate of isotope labelled uterine spermatozoa in the mouse post-coitum. Aust.J. Zool. 13, 525-531.

Rollhauser, H. (1949) Superfetation in a mouse. Anat. Rec. 105, 657-663.

Scrimgeour, J.B. \& Baker, T.G. (1974) A possible case of superfetation in man.J. Reprod. Fert. 36, 69-73.

Smirh, D. M., OURA, C. \& Zamboni, L. (1970) Fertilizing ability of structurally abnormal spermatozoa of the mouse. Nature, Lond. 227, 79-80.

StUdDIFORd, W.E. (1936) Is superfetation possible in the human being? Am. J. Obstet. Gynec. 31, 845-855.

SumNer, F.B. (1916) Notes on superfoetation and deferred fertilization among mice. Biol. Bull. mar. Biol. Lab., Woods Hole 30, 271-285.

WEICHERT, C.K. (1942) A case of parallel embryonic development in the rat and its bearing on the question of superfetation. Anat. Rec. 83, 511-519.

Wislocki, G.B. \& SNYdER, F.F. (1931) On the experimental production of superfetation. Johns Hopkins Hosp. Bull. 49, 103-105.

ZamBONI, L. (1972) Fertilization in the mouse. In Biology of Mammalian Fertilization and Implantation, pp. 213-262. Eds K. S. Moghissi \& E. S. E. Hafez. Charles C. Thomas, Springfield.

Received 17 June 1975 